\title{
Effect of Ferrite on the Precipitation of $\sigma$ Phase in Cast Austenitic Stainless Steel Used for Primary Coolant Pipes of Nuclear Power Plants
}

\author{
Yongqiang Wang ${ }^{a, b *}, \mathrm{Na} \mathrm{Li}{ }^{c}$ \\ ${ }^{a}$ School of Materials Science and Engineering, Anhui University of Technology, Maanshan, 243002, \\ Anhui Province, China \\ ${ }^{b}$ State Key Laboratory for Advanced Metals and Materials, University of Science and Technology, \\ 100083, Beijing, China \\ ${ }^{c}$ School of Metallurgical Engineering, Anhui University of Technology, Maanshan, 243002, Anhui \\ Province, China
}

Received: February 21, 2017; Revised: August 10, 2017; Accepted: August 24, 2017

\begin{abstract}
The effect of ferrite phase on the precipitation of $\sigma$ phase in a Z3CN20.09M cast austenitic stainless steel (CASS) used for primary coolant pipes of pressurized water reactor (PWR) nuclear power plants was investigated by using isothermal heat-treatment, optical microscopy (OM), transmission electron microscopy (TEM) and electron probe microanalysis (EPMA) techniques. The influence of different morphologies and volume fractions of ferrite in the $\sigma$ phase formation mechanism was discussed. The amount of $\sigma$ phase precipitated in all specimens with different microstructures increased with increasing of aging time, however, the precipitation rate is significant different. The formation of $\sigma$ phase in specimens with the coarsest ferrite and the dispersively smallest ferrite is slowest. The lowest level $\mathrm{Cr}$ content in ferrite and fewest $\alpha / \gamma$ interfaces in specimen are the main reasons for the slowest $\sigma$ precipitation due to they are unfavorable for the kinetics and thermodynamics of phase transformation respectively. By contraries, the fastest formation of $\sigma$ phase takes place in specimens with narrow and long ferrite due to the most $\alpha / \gamma$ interfaces and higher $\mathrm{Cr}$ content in ferrite which are beneficial for preferential nucleation and formation thermodynamics of $\sigma$ phase.
\end{abstract}

Keywords: Cast austenitic stainless steel, ferrite, $\sigma$ phase, precipitation behavior, microstructure.

\section{Introduction}

Cast austenitic stainless steels (CASS), which are characterized by the dual phase microstructure in which the island $\alpha$-ferrite phase distributes in the $\gamma$-austenite matrix, possess excellent synthesis mechanical properties, good workability and high resistance to localized corrosion in chloride environments ${ }^{1-4}$. Consequently, they are widely used in the primary coolant pipes of nuclear power plants and other engineering applications such as oil, chemical petrochemical, marine industries. However, several undesirable precipitated phases including $\alpha^{\prime}, \mathrm{M}_{23} \mathrm{C}_{6}, \sigma, \chi$, and $\pi$ can form in these steels when they are exposed to the temperature region from $320^{\circ} \mathrm{C}$ to $950^{\circ} \mathrm{C}$ for a period of time $e^{5-7}$. Generally, these secondary precipitates are harmful for properties of stainless steels.

Among all the precipitates mentioned above, $\sigma$ phase is usually considered to be the most harmful. The presence of $\sigma$ phase in stainless steels not only severely decreases the toughness of steels but also negatively impacts the corrosion resistance ${ }^{7,8}$. However, recently it is reported that the precipitation of $\sigma$ phase is beneficial for the creep strength and hot tensile strength of stainless steels although some researchers hold opposite views ${ }^{9,10}$. Because of its significant influence, the precipitation of $\sigma$ phase has been research by lots of workers. The results showed that the composition of alloys is the most important factor for $\sigma$ precipitation $^{11-13}$. Ferritic stabilizer such as $\mathrm{Cr}$, Mo and $\mathrm{Si}$ can promote the precipitation. In fact, the microstructure of stainless steels including grain size, $\alpha / \gamma$ interface ratio can affect the formation of $\sigma$ phase too ${ }^{11,14-16}$. Generally, $\sigma$ directly formed in $\alpha / \gamma$ dual phase stainless steels by the eutectoid decomposition, $\alpha \rightarrow \sigma+\gamma_{2}{ }^{17,18}$. So, ferrite phase may be one of important factors for the $\sigma$ precipitation in stainless steels especially for CASS with a dual phase microstructure that less ferrite phases distribute in austenite matrix. Up to now, however, very few attempts have been made to investigate the effect of ferrite on the precipitation of $\sigma$ phase in CASS. In this present work, the precipitation behavior of $\sigma$ phase in a Z3CN20.09M CASS used for primary coolant pipe of nuclear power plants with different volume and morphology ferrite was investigated. Meanwhile, the mechanism of ferrite effect was elucidated. 


\section{Experimental Materials and Methods}

The materials studied were cut from a Z3CN20.09M CASS primary coolant pipe of pressurized water reactor of nuclear power plants. The pipe was fabricated by electric-arc and argon-oxygen decarburization melting first, and then by moulded casting followed by air cooling and solution treatment $\left(1180^{\circ} \mathrm{C}, 8 \mathrm{~h}\right)$ followed by water quenching. The chemical composition of Z3CN20.09M CASS is C 0.024 , Si 1.09, Mn 1.11, P 0.023, S 0.0039, Cr 20.16, Ni 9.06, $\mathrm{Cu}$ 0.031, Co 0.026, Nb+Ta 0.066, Mo 0.26, N 0.033, Ti 0.0027 , Fe balance.

In order to illustrate the effect of ferrite on the precipitation of $\sigma$ phase, $\mathrm{Z3CN} 20.09 \mathrm{M}$ specimens with different microstructures were obtained by using different methods. Specimen A was annealed at $1350{ }^{\circ} \mathrm{C}$ for $20 \mathrm{~h}$, specimen $\mathrm{B}$ was hot forged at $1180^{\circ} \mathrm{C}$, specimen $\mathrm{C}$ was cut from the top of a part of primary coolant pipe and specimen $D$ was cut from the bottom of a part of primary coolant pipe (Fig.1). All the as-received specimens were aged at $750^{\circ} \mathrm{C}$ for different time to conveniently elucidate the precipitation behavior of $\sigma$ phase in Z3CN20.09M CASS with different microstructure, because the higher kinetics of $\sigma$ phase formation occurs at $750{ }^{\circ} \mathrm{C}^{19}$.

Specimens were ground by using wet abrasive paper up to $2000^{\#}$ and then polished using diamond paste to a finish of $1.5 \mu \mathrm{m}$, and finally rinsed in distilled water, ultrasonically cleaned and dried in air. Microstructures of specimens were revealed by electrolytic etching in a $20 \mathrm{wt} \% \mathrm{NaOH}$ distilled water solution at room temperature with direct voltage $3 \mathrm{~V}$ for $10 \mathrm{~s}$. Microstructures of the specimens were observed by CIKONG 4XCE optical microscopy (OM) after etching in the electrolyte. Volume fractions of precipitates, ferrite phase and the mean size of ferrite in the samples were obtained through the quantitative metallography analysis software (Image-Pro Plus 6.0) on 20 optical measurements for each specimen. The mean size of ferrite is denoted by mean length and width of ferrite phase. $\sigma$ phase in this steel were detected by JEOL JEM-2010 transmission electron microscopy (TEM). The quantitative compositions of the austenite and ferrite phase in the specimens were measured by JEOL JXA-8100 electron probe microanalysis technique (EPMA).

\section{Results and Discussion}

\subsection{Microstructure of as-received Z3CN20.09M CASS}

Fig.2 shows the microstructure of A, B, C and D four Z3CN20.09M CASS specimens with different ferrite phase, revealing that only austenite (gray) and ferrite (dark) phases exist in the steel. Fig. 3 displays the ferrite contents and ferrite mean sizes in these four specimens A, B, C, D. The values are about $37,12,13,8$ volume $\%$ and $230,96,98,18 \mu \mathrm{m}$ respectively. From Fig. 3, one can also see that the $\alpha / \gamma$ phase boundary ratio in specimen $A$ is the lowest level and that of specimen $B$ is the highest. Moreover, morphology of ferrite in four specimens is also obviously different. The ferrite in specimen A is the coarsest and the ferrite in specimen D is the smallest, while, the typical long and narrow ferrite can be found in specimen B (Fig. 2b).

By means of Thermo-Calc software, a phase diagram of the $\mathrm{Z3CN} 20.09 \mathrm{M}$ CASS using chromium as a variable was computed, and the result is shown in Fig. 4. The composition of the Z3CN20.09M CASS is indicated by a broken vertical line (Fig. 4a). It can be seen that the primary $\delta$-ferrite solidifies first and then the $\delta \rightarrow \gamma$ transformation takes place. The nucleation and growth of the austenite phase is a diffusion-controlled process which is affected strongly by the degree of super-cooling ${ }^{20}$. On rapid cooling, although the nucleation easily occurs in the ferrite phase, the growth of the austenite phase will be restrained due to insufficient time for the diffusion of alloy elements. Thus, the larger ferrite grains and also more ferrite remained in the structure of the Z3CN20.09M CASS pipe (Fig. 2c). By contrast, slow cooling (low cooling rate) would promote the diffusion of austenitic stabilized elements, such as $\mathrm{Mn}$, $\mathrm{N}$ and $\mathrm{Ni}^{21,22}$. Thus, more austenite formed from the ferrite phase, resulting in smaller ferrite phase in the inside of the pipe (Fig. 2d) $)^{21,23}$. When Z3CN20.09M CASS annealed at

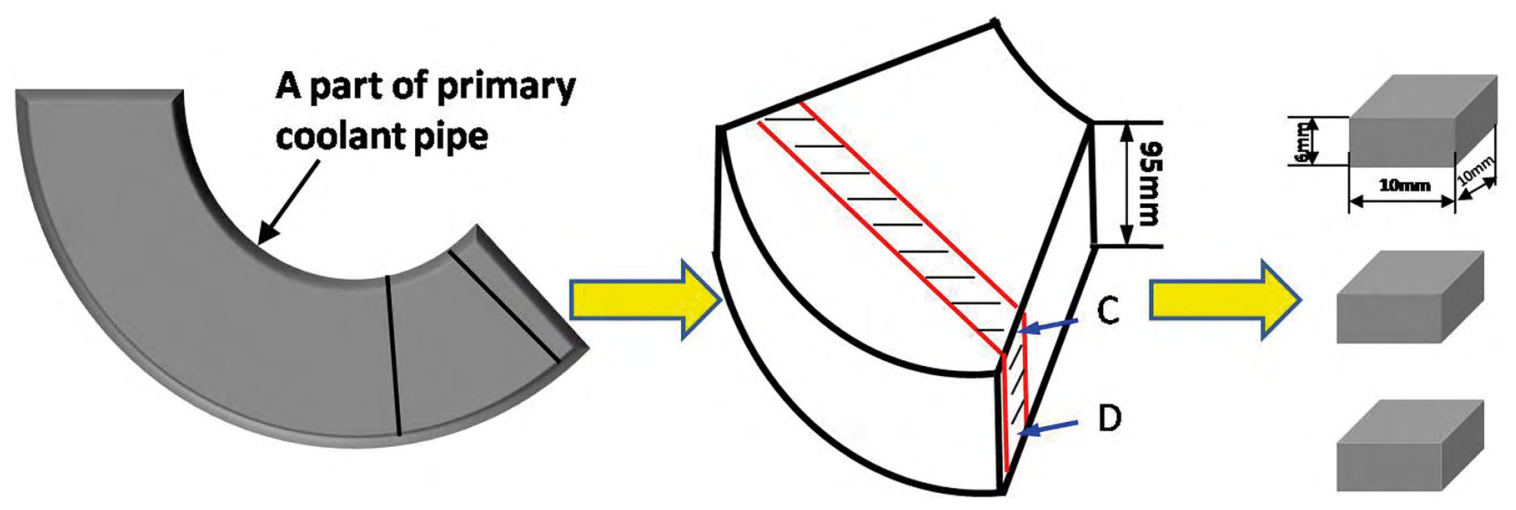

Figure 1. Specimen C and D of Z3CN20.09M CASS cut from the top and bottom of a part of primary coolant pipe. 


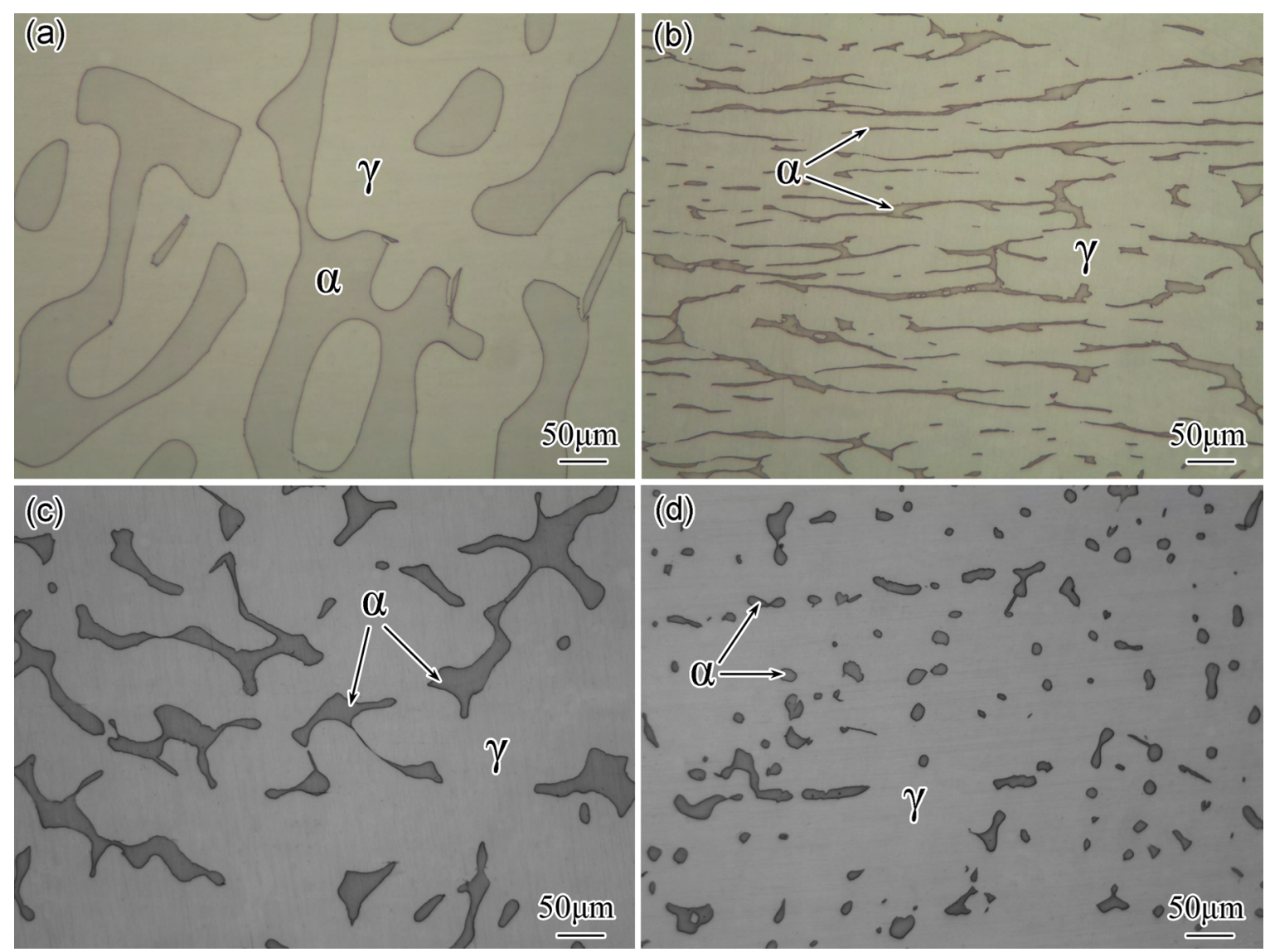

Figure 2. Microstructure of $\mathrm{Z} 3 \mathrm{CN} 20.09 \mathrm{M}$ specimens with different ferrite phase (a) annealed at $1350^{\circ} \mathrm{C}$, (b) hot forged, (c) containing $13 \%$ volume ferrite, (d) containing $8 \%$ volume ferrite, these specimens are named A, B, C, D respectively.

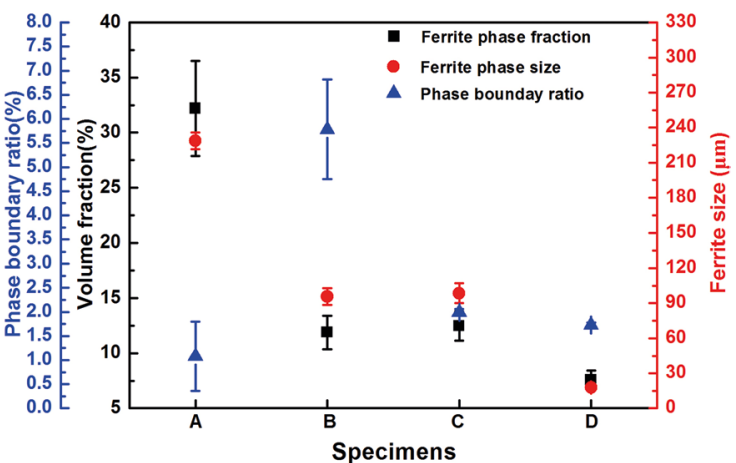

Figure 3. Four Z3CN20.09M primary coolant pipe specimens with different ferrite contents and sizes and austenite/ferrite phase boundaries.

high temperature, some austenite $(\gamma)$ would be transformed to ferrite $(\delta)$ in order to satisfy the thermodynamics equilibrium of austenite and ferrite phase. During the process of $\gamma \rightarrow \delta$ transformation, ferrite grains grown continuously by means of elements diffusion, so the volume fraction of ferrite increased and they become coarser. According to the phase diagram, on equilibrium state the ratio of $\gamma / \delta$ at $1350^{\circ} \mathrm{C}$ is nearly $1: 1$. This accords with the high temperature annealing experimental result approximately (Fig. 2a).

\subsection{Precipitation of $\sigma$ phase in Z3CN20.09M CASS with different microstructures}

Fig. 5 shows the optical microstructure of Z3CN20.09M steel with different ferrite aged at $750{ }^{\circ} \mathrm{C}$ for $1,24,50$ and $200 \mathrm{~h}$. In these four aged specimens, precipitates can be found and their volume fraction increased with aging time. It is sure that the precipitates are almost all $\sigma$ phases and a little $\mathrm{M}_{23} \mathrm{C}_{6}$ carbide at $\gamma / \alpha$ interface in terms of previous works ${ }^{19}$. Fig. 6 indicates the TEM micrograph of the Z3CN20.09M specimen aged at $750{ }^{\circ} \mathrm{C}$ for $200 \mathrm{~h}$, detecting the $\sigma$ phase with a tetragonal structure and secondary austenite $\left(\gamma_{2}\right)$ with FCC structure. Although, the amount of $\sigma$ phase in all specimens increased with the increase of aging time, the precipitation rate (or transformation ratio of $\alpha \rightarrow \sigma$ ) is significant different. Less $\sigma$ phase precipitated in the aged specimens A with more and coarse ferrite than that in others at the same aging time. However, the most $\sigma$ phase precipitated in the aged specimens $\mathrm{B}$ at the same aging time. Fig. 7 displays the transformation ratio of ferrite in different specimens. One can see that when aging for the same time, for example $24 \mathrm{~h}$, the transformation ratio of $\alpha \rightarrow \sigma$ in aged specimen $A$ is the minimum level and about $10 \%$, while, the value in specimen $B$ is the maximum and higher than $50 \%$. This indicates the coarser the ferrite, 

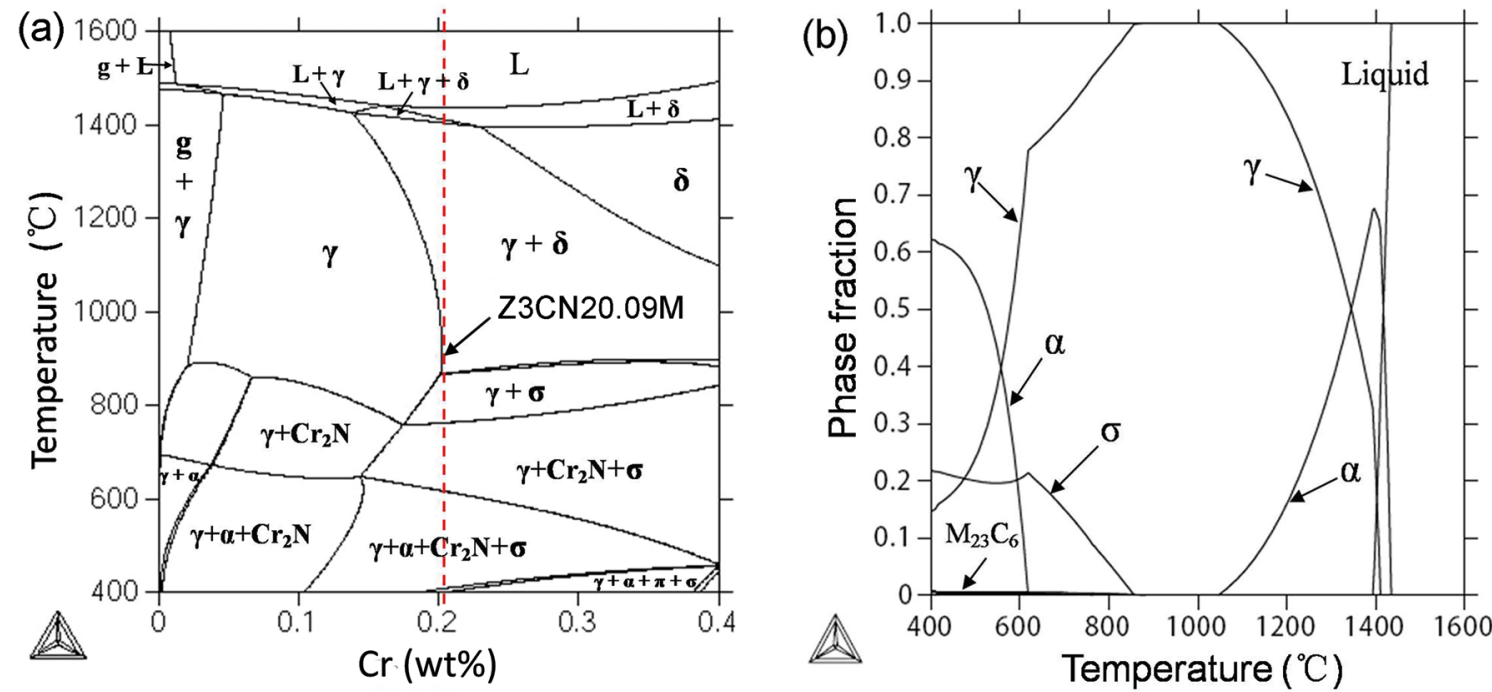

Figure 4. Phase diagram of $\mathrm{Z} 3 \mathrm{CN} 20.09 \mathrm{M}$ computed using Thermo-Calc software (a) the composition of Z3CN20.09M is indicated by a dashed line, (b) phase fractions of ferrite, austenite, $\sigma$-phase and $\mathrm{M}_{23} \mathrm{C}_{6}$ as a function of temperature.

the slower the formation of $\sigma$ phase and the narrower or finer the ferrite, the faster the precipitation of $\sigma$ phase. It is necessary to discuss the mechanism of microstructure effect on $\sigma$ formation behavior for elucidating the phenomenon.

\subsection{Mechanism of $\sigma$ precipitation in Z3CN20.09M CASS dependent on microstructure}

The precipitation behavior of $\sigma$ phase in stainless steels depends on many factors including chemical compositions, heat-treatment process and microstructure, etc ${ }^{11}$. Ferrite is very important for cast austenitic stainless steels and plays an important role in the properties of cast austenitic stainless steels. There is always higher $\mathrm{Cr}$ and Mo concentrations in ferrite phase since $\mathrm{Cr}$, Mo are ferrite stabilized elements. Because $\mathrm{Cr}$ and Mo facilitate $\sigma$ phase precipitation significantly, so ferrite is a beneficial site for the precipitation of the $\sigma$ phase $^{24}$. It is well known that $\sigma$ precipitates in duplex stainless steels by the eutectoid decomposition of $\alpha$ ferrite: $\alpha \rightarrow \sigma$ $+\gamma_{2}$ and its nucleation and growth from ferrite to the $\alpha / \alpha$ grain boundaries or $\alpha / \gamma$ interfaces strongly depends on $\mathrm{Cr}-$ diffusion ${ }^{25}$. On one hand, there are the most high energy $\alpha / \gamma$ phase boundaries in specimen B (Fig.2, 3), which provide many preferential sites for $\sigma$ nucleation. Furthermore, the diffusion of $\mathrm{Cr}$ in these interfaces is fast and beneficial for growth of $\sigma$ phase. On the other hand, $\mathrm{Cr}$ content of ferrite in specimen $\mathrm{B}$ is much higher (about $26 \%$, Fig. 8 ) and is close to the value of $\mathrm{Cr}$ in $\sigma$ phase $^{26}$. Thermodynamically, this ferrite with more solid solution $\mathrm{Cr}$ is also more beneficial for $\sigma$ phase formation. Compared with other specimens, there are not only the fewest $\alpha / \gamma$ interfaces but also the lowest $\mathrm{Cr}$ content of ferrite in specimen A. These are unfavorable for nucleation and growth of $\sigma$ phase from both kinetics and thermodynamic aspects. Therefore, the formation of $\sigma$ phase is the fastest in specimen B and the slowest in specimen A. Although there are almost the same $\mathrm{Cr}$ content of ferrite and phase boundaries in specimens $\mathrm{C}$ and $\mathrm{D}$, the size and volume fraction of ferrite in specimen $\mathrm{D}$ is smaller and fewer than those in specimen C (Fig. 3, 5). Moreover, the ferrite phases in specimen D are also more dispersive (Fig. 3). As a result, the concentration of $\mathrm{Cr}$, Mo elements in specimen $\mathrm{D}$ may be more uniform. It is relatively difficult to obtain $\mathrm{Cr}$, Mo concentration fluctuation that is necessary for solid phase transformation. This is unfavorable for nucleation of $\sigma$ phase. Whereas, the aggregated larger and more ferrite phases in specimen $\mathrm{C}$ not only provide more sites for $\sigma$ phase formation, but also easily induce the concentration fluctuations of $\mathrm{Cr}$, Mo elements. Those can promote $\sigma$ phase precipitation. Thereby, the formation of $\sigma$ phase in specimen $\mathrm{C}$ is faster than that in specimen $\mathrm{D}$ even if there is a similar thermodynamics for $\sigma$ phase precipitation in specimens $C$ and $\mathrm{D}$ because of the almost same $\mathrm{Cr}$ content in ferrite phase of the two specimens.

\section{Conclusions}

1. Although, the volume fraction of $\sigma$ phase in all Z3CN20.09M CASS specimens with four ferrite phase specimens increased with aging time, there is markedly difference in the $\sigma$ formation rate.

2. The precipitation of $\sigma$ phase in specimens with the maximum and coarsest ferrite (specimen A) and with fewest and smallest dispersive ferrite (specimen D) is the lowest. By contraries, the formation of $\sigma$ phase in specimen with narrow and long ferrite 


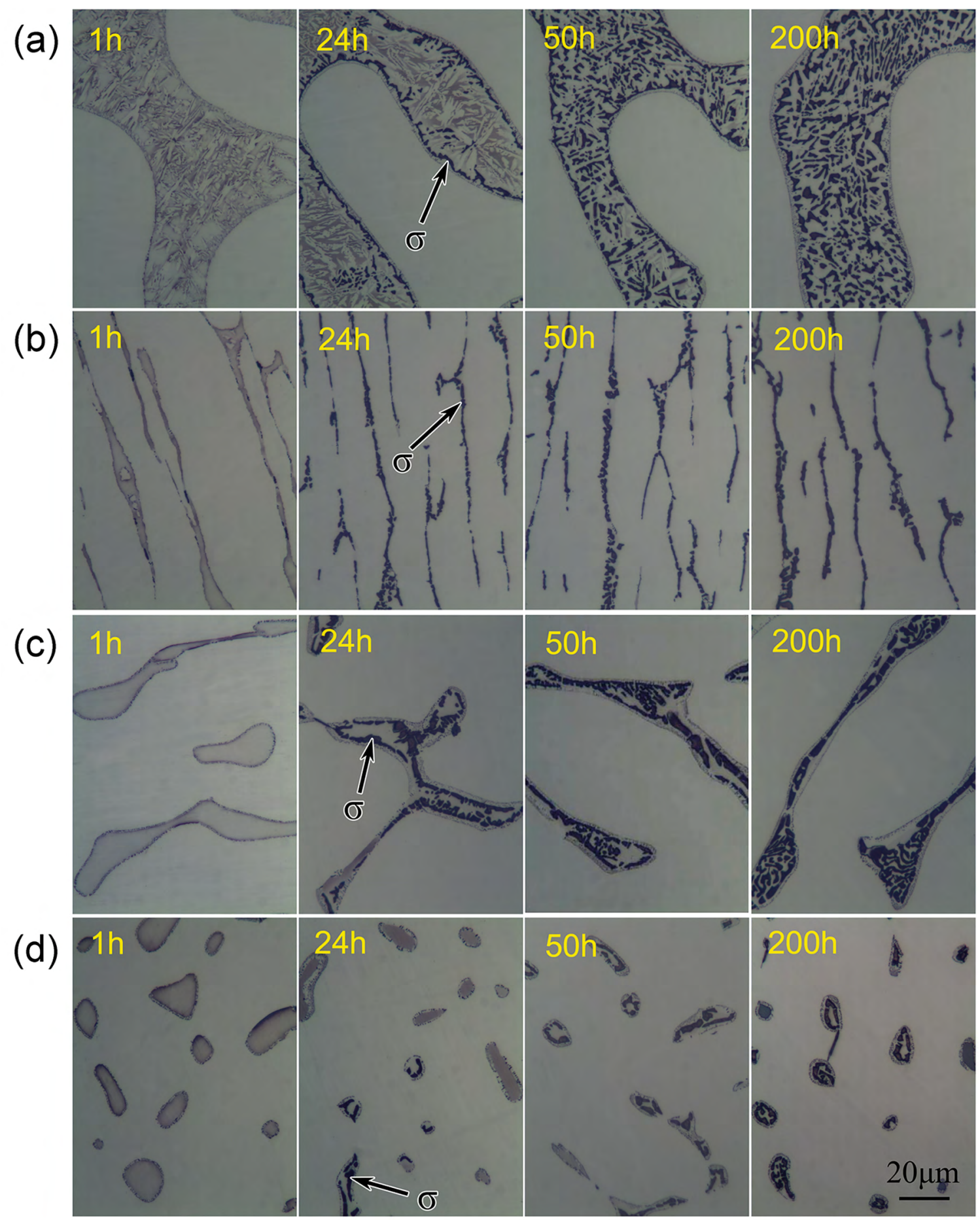

Figure 5. OM photographs of $\mathrm{Z3CN} 20.09 \mathrm{M}$ specimens with different microstructure aged at $750^{\circ} \mathrm{C}$ for different times (a) specimen $\mathrm{A}$, (b) specimen B, (c) specimen C, (s) specimen D.

(specimen B) is the fastest. The faster formation, while, takes place in specimen with aggregated larger and more ferrite (specimen $\mathrm{C}$ ).

3. The lowest level $\mathrm{Cr}$ content in ferrite and fewest $\alpha / \gamma$ interfaces in specimen are the reason for the slowest precipitation of $\sigma$ phase due to they are unfavorable for the kinetics and thermodynamics of phase transformation respectively.

4. The dispersive small ferrite is favorable for Z3CN20.09M CASS owing to that restrains the $\sigma$ phase precipitation. 


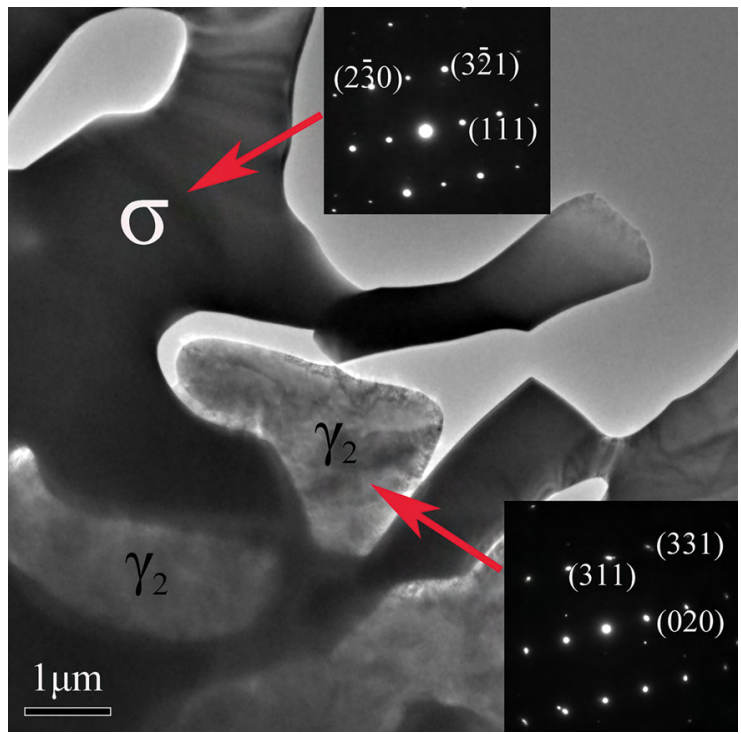

Figure 6. TEM micrograph of the $\mathrm{Z} 3 \mathrm{CN} 20.09 \mathrm{M}$ specimen aged at $750{ }^{\circ} \mathrm{C}$ for $200 \mathrm{~h}$.

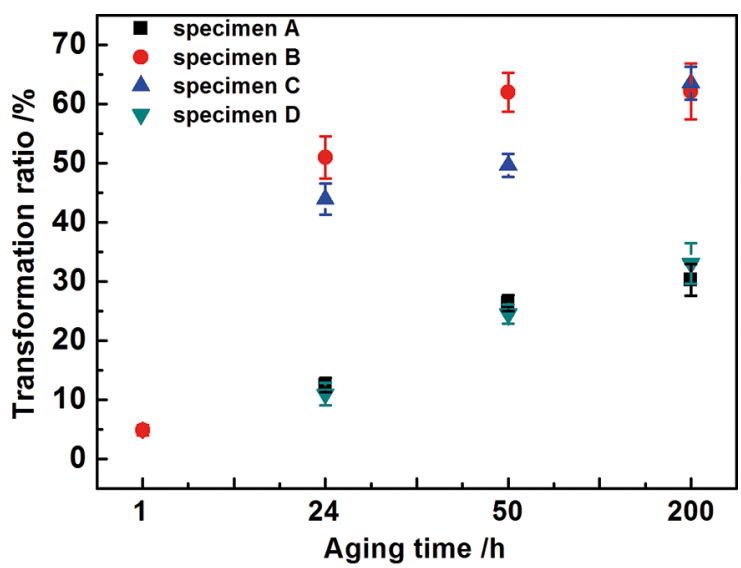

Figure 7. Transformation ratio of $\alpha \rightarrow \sigma$ in specimens with different microstructure aged at $750^{\circ} \mathrm{C}$ for different time.

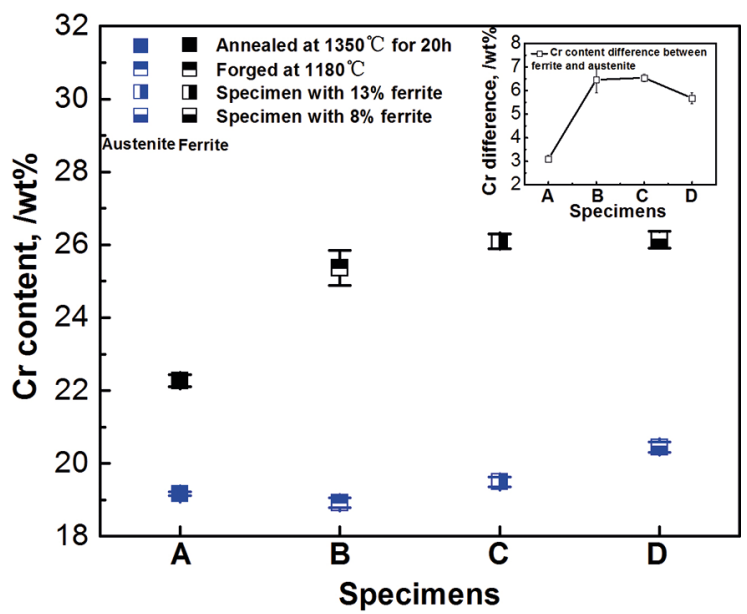

Figure 8. Cr content in $\mathrm{Z} 3 \mathrm{CN} 20.09 \mathrm{M}$ specimens with different ferrite

\section{Acknowledgements}

This work was financially supported by the National Natural Science Foundation of China [grant number 51501001] and Anhui Provincial Natural Science Foundation [grant number 1508085QE102].

\section{References}

1. Xue F, Wang ZX, Shu GG, Yu WW, Shi HJ, Ti WX. Thermal aging effect on Z3CN20.09M Cast Duplex Stainless Steel. Nuclear Engineering and Design. 2009;239(11):2217-2223.

2. Park JS, Yoon YK. Evaluation of thermal aging embrittlement of duplex stainless steels by electrochemical method. Scripta Metallurgica et Materialia. 1995;32(8):1163-1168.

3. Yi YS, Shoji T. Detection and evaluation of material degradation of thermally aged duplex stainless steels: electrochemical polarization test and AFM surface analysis. Journal of Nuclear Materials. 1996;231(1-2):20-28.

4. Yi YS, Shoji T. Quantitative evaluation of material degradation of thermally aged duplex stainless steels using chemical immersion test. Journal of Nuclear Materials. 1996;240(1):62-69.

5. Nilsson JO. Super duplex stainless steels. Materials Science and Technology. 1992;8(8):685-700.

6. Gunn RN, ed. Duplex Stainless Steels: Microstructure, Properties and Applications. Cambridge: Abington; 1997.

7. Ezuber HM, El-Houd A, El-Shawesh F. Effects of sigma phase precipitation on seawater pitting of duplex stainless steel. Desalination. 2007;207(1-3):268-275.

8. Pohl M, Storz O, Glogowski T. Effect of intermetallic precipitations on the properties of duplex stainless steel. Materials Characterization. 2007;58(1):65-71.

9. Wang YQ, Han J, Yang B, Wang XT. Strengthening of $\sigma$ phase in a Fe20Cr9Ni cast austenite stainless steel. Materials Characterization. 2013;84:120-125.

10. Shek CH, Li DJ, Wong KW, Lai JKL. Creep properties of aged duplex stainless steels containing $\sigma$ phase. Materials Science and Engineering: A. 1999;266(1-2):30-36.

11. Maehara Y, Ohmori Y, Murayama J, Fujino N, Kunitake T. Effects of alloying elements on $\sigma$ phase precipitation in $\delta-\gamma$ duplex phase stainless steels. Metal Science. 1983;17(11):541548 .

12. Lin DY, Chang TC, Liu GL. Effect of Si contents on the growth behavior of $\sigma$ phase in SUS 309L stainless steels. Scripta Materialia. 2003;49(9):855-860.

13. Hsieh CC, Wu W. Overview of Intermetallic Sigma $(\sigma)$ Phase Precipitation in Stainless Steels. ISRN Metallurgy. 2012;2012:732471

14. Sato YS, Kokawa H. Preferential precipitation site of sigma phase in duplex stainless steel weld metal. Scripta Materialia. 1999;40(6):659-663. 
15. Schwind M, Källqvist J, Nilsson JO, Ågren J, Andrén HO. $\sigma$-phase precipitation in stabilized austenitic stainless steeels. Acta Materialia. 2000;48(10):2473-2481.

16. Sourmail T, Bhadeshia HKDH. Modelling simultaneous precipitation reactions in austenitic stainless steels. Calphad. 2003;27(2):169-175.

17. Elmer JW, Palmer TA, Specht ED. In situ observations of sigma phase dissolution in 2205 duplex stainless steel using synchrotron X-ray diffraction. Materials Science and Engineering: A. 2007;459(1-2):151-155.

18. Wong KW, Shek CH, Zhang W, Lai JKL. $\sigma$ phase dissolution in duplex stainless steel at elevated temperature studied by thermal analysis. Materials Letters. 2008;62(24):3991-3994.

19. Wang YQ, Han J, Yang B, Wu HC, Wang XT. Precipitation behavior of the intermetallic phases in Z3CN20.09M stainless steel for primary coolant pipes of nuclear. Acta Metallurgica Sinica. 2013;49(4):415-420.

20. Lu BT, Chen ZK, Luo JL, Patchett BM, Xu ZH. Pitting and stress corrosion cracking behavior in welded austenitic stainless steel. Electrochimical Acta. 2005;50(6):1391-1403.
21. Chen L, Tan H, Wang Z, Li J, Jiang Y. Influence of cooling rate on microstructure evolution and pitting corrosion resistance in the simulated heat-affected zone of 2304 duplex stainless steels. Corrosion Science. 2012;58:168-74.

22. Sourmail T. Precipitation in creep resistant austenitic stainless steels. Materials Science and Technology. 2001;17(1):1-14.

23. Kordatos JD, Fourlaris G, Papadimitriou G. The effect of cooling rate on the mechanical and corrosion properties of SAF 2205 (UNS 31803) duplex stainless steel welds. Scripta Materialia. 2001;44(3):401-408.

24. Redjaimia A, Metauer G, Gantois M. Decomposition of Delta Ferrite in an Fe-22Cr-5Ni-3Mo-0.03C Duplex Stainless Steel. A Morphological and Structural Study. In: Proceedings of Duplex Stainless Steels '91; 1991 Oct 28-30; Beaune, France. p. 119-126.

25. Magnabosco R. Kinetics of sigma phase formation in a Duplex Stainless Steel. Materials Research. 2009;12(3):321-327.

26. Wang YQ, Yang B, Han J, Wu HC, Wang XT. Effect of Precipitated Phases on the Pitting Corrosion of Z3CN20.09M Cast Duplex Stainless Steel. Materials Transactions. 2013;54(5):839-843. 